\title{
Mediocrity has become the norm, Turnbull asserts in valedictory address
}

I llnesses prolonged because of unaffordable medications. Operations cancelled because of hospital overcapacity. Debilitating pain because of delayed knee joint replacements. Millions of Canadians without family doctors. This is Canada's health care system. And it's a system Canadians can no longer take pride in, says outgoing Canadian Medical Association President Dr. Jeffrey Turnbull.

"We have seen a slow but steady decline in what we would all now agree is a deeply troubled health care system,' Turnbull told delegates at the CMA's 144th annual general meeting in St. John's, Newfoundland and Labrador, during his valedictory speech on Aug. 23. "To be clear, this pillar of Canadian society is eroding."

And it's only getting worse, said Turnbull, noting that Canada's health care system continues to fall down the ranks internationally in areas such as value for money spent and effectiveness. Turning things around, Turnbull suggested, will require tackling social inequalities, shifting focus from acute care to chronic illnesses and improving leadership in the medical profession.

Over the past year, Turnbull has travelled extensively across the country, and he noted that patients and physicians alike are unhappy with the health care system. Many patients expressed concerns about a lack of timely access to effective care, are confused by a cumbersome system that supports some services but not others, and are angry that their concerns go unheard and their needs unmet.

Physicians, meanwhile, are frustrated by a lack of vision in their profession, said Turnbull. They fear that many doctors have become apathetic or only support causes that line their pocketbooks.
Mediocrity has become the accepted norm, said Turnbull, and health care transformation is considered a mountain too big to climb. "Like you, like patients and other providers, I have been struck by this lack of leadership, coordinated management, accountability and responsibility, and, yes, we see needless waste. But I honestly believe that change is afoot."

That change, according to Turnbull, starts with the CMA's health care transformation initiative, as it contains many important principles, and even more importantly, offers proof that physicians and health care organizations across the nation can reach a consensus on what matters most.

One important change that should occur, said Turnbull, is a slowing of the increasing social inequity in Canada, which leads to health inequities and higher costs. A vital step in that direc-

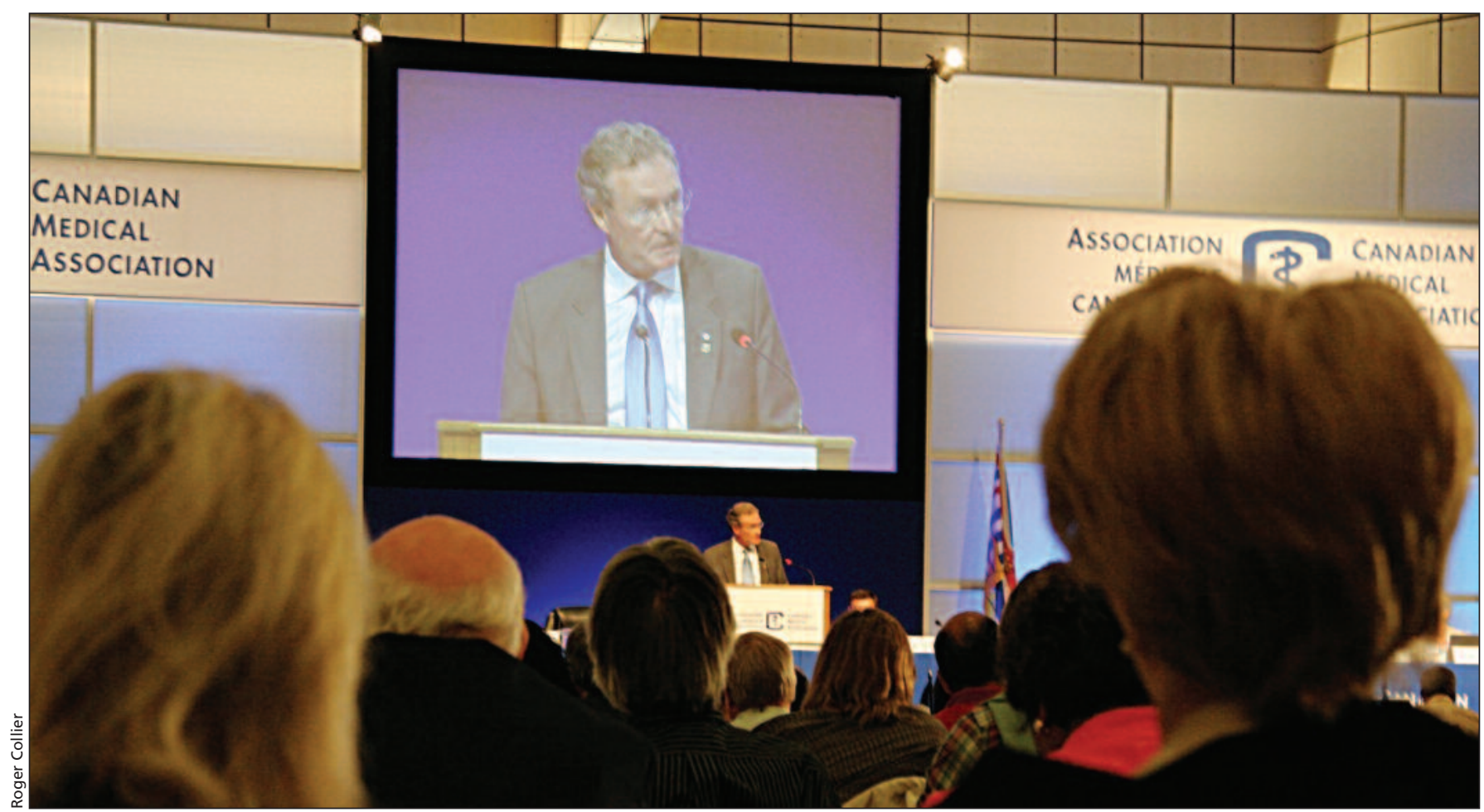

Outgoing Canadian Medical Association President Dr. Jeffrey Turnbull delivers his valedictory address to the CMA's 144th annual general meeting in St. John's, Newfoundland and Labrador, on Aug. 23. 
tion is the need to offer basic levels of prescription drug coverage to citizens, including the poor, the mentally ill, the elderly, Aboriginal populations and other groups that are often neglected.

The current "mish-mash" of public and private financing for medication is unacceptable, said Turnbull. "Creating a national drug strategy or pharmacare plan and a similar vision for long-term care are the two key features to establishing the next generation of medicare."

The health care system must also shift from an "acute care paradigm" to a model focused on treating the chronically ill, Turnbull added. This will require new management systems, partnerships, accountability structures and a team-based, patient-centred approach to meeting health needs in the home.

But substantial change will never occur unless physicians take the lead, Turnbull said. Doctors are the stewards of the health care system, not govern- ments, he argued. "In my view, they can only follow. It is our role to create the consensus, the partnerships, the circumstances to allow them to move forward and bring change to the struggling health care system."

As to his thoughts on his tenure at the helm of CMA, Turnbull said in an earlier interview that the end of his term left him with mixed emotions. On the one hand, it provided him with an incredible opportunity to speak to many people on topics he is passionate about. "I was able to speak about poverty and inequalities, and I heard from people who were really engaged," he says.

But the downside of being the voice of a nation's medical profession is that you rarely get a chance to rest that voice. The past year was busier than he thought it would be, full of meetings and forums and media interviews and policy reviews and other matters that required his attention at a moment's notice. Even many weekends were devoted to CMA work. "It's like being on call," says Turnbull. "You have to be available at all times."

Of course, Turnbull still plans to keep busy in the upcoming year. In addition to his regular work at The Ottawa Hospital in Ontario and Ottawa Inner City Health, he will be part of a steering committee on a new national strategy for patient-oriented research. In the fall, he will return to Bangladesh to make sure things are running well at a hospital and orphanage in a village he often visits. He will also be working as a medical adviser to the Canadian government on health services delivery in federal prisons. "That will replace my CMA work, figuring out how to deliver effective health care for national inmates," says Turnbull. "Those are my kind of people." — Roger Collier, CMAJ

CMAJ 2011. DOI:10.1503/cmaj.109-3982 